\title{
Treatment with Methimazole in a 3-Year-Old Male with Thyroid Hormone Resistance
}

\author{
Sarah L. Tsai Alexandra Ahmet \\ Division of Endocrinology, Children's Hospital of Eastern Ontario, University of Ottawa, Ottawa, Ont., Canada
}

\section{Established Facts}

- Thyroid hormone resistance (THR) syndromes are disorders in which there is decreased end-organ responsiveness to thyroid hormone.

- Patients typically present with elevated levels of thyroxine (T4) and triiodothyronine (T3) with a normal or increased serum thyroid-stimulating hormone (TSH) concentration.

- Clinical features are variable, and there are no guidelines regarding treatment.

\section{Novel Insights}

- We describe the use of methimazole for treatment of genetically confirmed pituitary THR in a pediatric patient presenting with hyperactive behavior, poor weight gain, sinus tachycardia and subtle developmental delay.

- Sleeping habits, behavior and tachycardia improved with methimazole. His heart rate remains in the upper normal range and his thyroid is more enlarged.

- The patient will require screening for the theoretical risk of pituitary hyperplasia secondary to iatrogenic hyperthyrotropinemia.

\section{Key Words}

Thyroid hormone resistance $\cdot$ Thionamides $\cdot$ Thyroid hormone receptor- $\beta$ gene mutation

\section{Abstract \\ Background: Thyroid hormone resistance syndromes are disorders in which there is decreased end-organ responsive- ness to thyroid hormone. Patients typically present with el- evated levels of thyroxine and triiodothyronine with a nor-}

mal or increased serum thyroid-stimulating hormone concentration. Clinical features are variable, and there are no guidelines regarding treatment. Patient: The patient was noted to have tachycardia at 6 months of age. He had persistently elevated free thyroxine and normal/mildly elevated thyroid-stimulating hormone for the first 2 years of life. At age 2 years, he was noted to have sinus tachycardia, a mildly enlarged thyroid, hyperactive behavior, subtle developmental delay, and poor weight gain. The patient has a previously described de novo mutation in the thyroid hormone recep-

\section{KARGER}

Fax +4161306 1234

E-Mail karger@karger.ch

www.karger.com
(C) 2012 S. Karger AG, Basel

$1663-2818 / 12 / 0776-0402 \$ 38.00 / 0$

Accessible online at:

www.karger.com/hrp
Sarah L. Tsai, MD

Division of Endocrinology, Children's Hospital of Eastern Ontario

University of Ottawa, 401 Smyth Road

Ottawa, ON K1H 8L1 (Canada)

Tel. +1 6137377600 , ext. 3939, E-Mail s.lenihan.tsai@gmail.com 
tor- $\beta$ gene. Intervention and Outcomes: He was started on methimazole $(0.3-0.5 \mathrm{mg} / \mathrm{kg} /$ day) at age 3 years to treat his symptoms. With medication, weight gain, sleep, behavior, and tachycardia improved. Linear growth has remained appropriate for age. Heart rate is in the upper normal range and his thyroid has become more enlarged. Conclusions: Methimazole has improved thyrotoxic symptoms in a 3-yearold male with thyroid hormone resistance. The use of methimazole should be considered in certain patients.

Copyright ๑ 2012 S. Karger AG, Basel

\section{Introduction}

THR syndromes are disorders in which there is decreased end-organ responsiveness to thyroid hormone. The incidence of THR is estimated to be 1 in 40,000 live births [1]. THR is caused by mutations in the thyroid hormone receptor gene. It is generally transmitted in an autosomal dominant fashion. Patients typically present with elevated levels of T4 and T3 with a normal or increased serum TSH concentration. The clinical features are variable and there are no guidelines regarding treatment. Methimazole has been used to treat thyrotoxic symptoms in a paucity of reported patients with THR, often as initial treatment in patients who were inappropriately diagnosed with hyperthyroidism. In certain circumstances, anti-thyroid medications may prove beneficial for patients with predominantly thyrotoxic symptoms.

\section{Case Report}

The patient is a male of Western European Caucasian ethnicity who was noted to have tachycardia at 6 months of age. The tachycardia persisted at all of his 'well-baby' visits. Thyroid function tests were performed as part of the workup to explore the etiology of tachycardia. He had persistently elevated free T4 and normal/mildly elevated TSH for the first 2 years of life (see table 1). He was referred to endocrinology for persistently elevated free T4 and free T3 in the context of a normal TSH.

Initial assessment by endocrinology was at 2 years 2 months of age. He was noted to have a heart rate of 125 beats per minute with an otherwise normal cardiac exam, a mildly enlarged thyroid gland, hyperactive behavior, and subtle developmental delay. He was prepubertal. Deep tendon reflexes were normoactive, he had no tremor, and no ophthalmopathies or proptosis. The patient developed worsening hyperactivity, poor sleep, delayed developmental milestones, and had no weight gain over the subsequent 9 months. Bone age done at initial assessment was congruent with chronological age. His hearing test was normal. Echocardiogram was normal, and electrocardiogram revealed sinus tachycardia.

Methimazole Use in Thyroid Hormone Resistance
He was started on methimazole $(0.3 \mathrm{mg} / \mathrm{kg} /$ day initially, then increased to $0.5 \mathrm{mg} / \mathrm{kg} /$ day due to lack of clinical response) at age 3 years to treat his symptoms. Developmental assessment at age 3 years revealed normal gross motor and self-help function; however, fine motor and social skills were at a 24-month-old level, and expressive language was at a 30-month-old level, with receptive language being slightly better. He was described by his daycare worker as being aggressive. Since starting the medication, he has gained weight and his sleep patterns and behavior have improved. His heart rate remains in the high normal range for age (100-115 BMP), and his thyroid gland has become more enlarged. Methimazole dose has ranged from 0.3 to $0.5 \mathrm{mg} / \mathrm{kg} /$ day in attempt to balance symptoms with biochemical profile (table 1). At age 3 years 6 months (42 months), developmental assessment revealed fine motor skills at a 33-month-old level, receptive language at a 33- to 36-month-old level, and expressive language at a 26 - to 30 -month-old level. Assessment at 44 months revealed a transient period of worsening behavior and regression in terms of toilet training. Methimazole therapy was increased based on symptomatology, but no changes in behavior were noted. Because of a rising TSH in the absence of improved behavior, methimazole dose was reduced to the previous dose of $0.3 \mathrm{mg} /$ $\mathrm{kg} /$ day. Four weeks later, during a developmental assessment, behavior was again improved despite no changes in therapy or biochemical markers. His unaffected dizygotic twin sister has had normal growth and development with no concerns about behavior.

The patient has a de novo mutation in the thyroid hormone receptor (TR)- $\beta$ gene. There has been an insertion of a cysteine at nucleotide 1644 (exon 10) resulting in a frameshift mutation and non-sense sequence terminating with the extension of the TR- $\beta$ protein with two additional amino acids. This mutation has been described in previous studies [2-4]. His parents and dizygotic twin sister have normal thyroid function tests (see table 2). Informed consent was obtained from the patient's parents regarding cytogenetic testing and thyroid function tests.

\section{Discussion}

\section{Clinical Presentation}

THR has been classified into three subtypes: generalized, pituitary and peripheral. Interestingly, individuals with the same mutation may exhibit different phenotypes [5]. Tachycardia occurs in $75-94 \%$ of patients with THR and is often the finding that prompts diagnosis [5]. The reasons for the variation in clinical presentation are poorly understood. In generalized THR, the patient is frequently clinically euthyroid due to compensatory increase in thyroid hormone concentrations. Other patients may present with combined symptoms suggestive of thyroid hormone excess and thyroid hormone deficiency; this mixed picture is postulated to be secondary to variable sensitivity of the peripheral tissues to thyroid hormone [6]. In pituitary THR (PTHR), the patients may present with hyperthyroid symptoms such as attention 
Table 1. Patient's thyroid function tests before and after treatment with methimazole

\begin{tabular}{lrrr}
\hline Age of patient & FT4, pmol/l & FT3, pmol/l & TSH, mIU/l \\
\hline Before treatment & & & \\
2 years 3 months & $20.1(8.7-16)$ & $16.5(3.3-6.0)$ & $2.94(0.5-5.5)$ \\
2 years 6 months & $18.1(8.7-16)$ & $16(3.3-6.0)$ & $4.43(0.5-5.5)$ \\
3 years & $80(11-37)$ & $24.4(3.3-6.9)$ & $2.79(0.8-6.5)$ \\
\hline After treatment & & & \\
3 years 1 month, $0.3 \mathrm{mg} / \mathrm{kg} /$ day methimazole & $62(11-37)$ & $19.7(3.3-6.9)$ & $7.14(0.8-6.5)$ \\
3 years 2 months, $0.5 \mathrm{mg} / \mathrm{kg} /$ day methimazole & $61(11-37)$ & $27(3.3-6.9)$ & $24(0.8-6.5)$ \\
3 years 4 months, $0.5 \mathrm{mg} / \mathrm{kg} /$ day methimazole & $22(11-37)$ & $13.5(3.3-6.9)$ & $307.9(0.8-6.5)$ \\
3 years 5 months, $0.3 \mathrm{mg} / \mathrm{kg} /$ day methimazole & $46(11-37)$ & $22.6(3.3-6.9)$ & $51.6(0.8-6.5)$ \\
3 years 7 months, $0.3 \mathrm{mg} / \mathrm{kg} /$ day methimazole & $66(11-37)$ & $31.6(3.3-6.9)$ & $18.7(0.8-6.5)$ \\
3 years 8 months, $0.5 \mathrm{mg} / \mathrm{kg} /$ day methimazole & $42(11-37)$ & $17.7(3.3-6.9)$ & $47.1(0.8-6.5)$ \\
4 years, $0.3 \mathrm{mg} / \mathrm{kg} / \mathrm{day} \mathrm{methimazole}$ & $61(11-37)$ & $\mathrm{N} / \mathrm{A}$ & $18.8(0.8-6.5)$ \\
\hline
\end{tabular}

Figures in parentheses indicate normal values. FT4 = Free serum T4; FT3 = free serum T3; N/A = not available. Please note - different range of normal values is due to a change in laboratory assay that occurred during this patient's care.

Table 2. Thyroid function tests of patient and family members

\begin{tabular}{lllll}
\hline Laboratory value & $\begin{array}{l}\text { Patient's father } \\
\text { (age 34) }\end{array}$ & $\begin{array}{l}\text { Patient's mother } \\
\text { (age 34) }\end{array}$ & $\begin{array}{l}\text { Sister (age 3 years } \\
\text { 3 months) }\end{array}$ & $\begin{array}{l}\text { Patient (age 3 years } \\
\text { 3 months) }\end{array}$ \\
\hline TT4 $(64-154), \mathrm{nmol} / \mathrm{l}$ & 110 & 119 & 123 & $239(\uparrow)$ \\
TT3 $(0.9-1.85), \mathrm{ng} / \mathrm{ml}$ & 1.24 & 1.41 & 1.85 & $3.27(\uparrow)$ \\
TrT3 $(245-553), \mathrm{pmol} / \mathrm{l}$ & 437 & 393 & 450 & $1,245(\uparrow)$ \\
TSH $(0.4-3.6), \mathrm{mIU} / \mathrm{ml}$ & 2.8 & 2.6 & 2.5 & $48(\uparrow)$ \\
TG $(1-35), \mathrm{ng} / \mathrm{ml}$ & 24 & 11 & 20 & $>100(\uparrow)$ \\
TPO and TG Ab (negative) & negative & negative & negative & negative \\
\hline
\end{tabular}

Figures in parentheses indicate normal values. TT4 = Total serum thyroxine; TT3 = total serum triiodothyronine; $\operatorname{TrT} 3=$ total serum reverse triiodothyronine; $\mathrm{TG}=$ thyroglobulin; $\mathrm{TPO}=$ thyroid peroxidase; $\mathrm{Ab}=\mathrm{an}$ tibody.

deficit hyperactivity, failure to thrive and hyperkinetic behavior [6]. These patients have inappropriately elevated TSH secretion with overproduciton of T4 and T3. Patients with genotypes that result in a frameshift mutation producing a mutant thyroid hormone- $\beta$ gene with a nonsense sequence and a 2 -amino-acid carboxyl-terminal extension, such as our patient, have particularly severe PTHR [4]. In peripheral THR, the patient will present with hypothyroidism symptoms, such as growth retardation, delayed bone maturation, and intellectual impairment. In this case, the sensitivity of the peripheral tissues to thyroid hormones is decreased relative to that of the pituitary.

\section{Treatment Options}

There is no existing therapy that will correct the defect in thyroid hormone receptor function. Patients with adequate compensation through an increase in T4 production, without thyrotoxic symptoms, do not require treatment. Patients who have hypothyroid symptoms may benefit from supraphysiologic doses of thyroid hormone [7]. In children, exogenous thyroid hormone may be considered for patients with seizure, developmental delay, extreme hyperthyrotropinemia, failure to thrive, or a history of poor growth or mental retardation in affected siblings [7]. Supraphysiologic doses of levo-T3 have successfully reduced a large goiter in a patient with THR and no symptoms of thyroid dysfunction [8]. 
The management of patients with hyperthyroid symptoms is somewhat controversial. The administration of antithyroid medications such as methimazole will cause a rise in TSH production and increase goiter. As a result, there is a theoretical risk for pituitary thyrotropic cell adenomas [9]. Some authors note that high levels of circulating thyroid hormone in these patients is an adaptive response to tissue resistance; therefore, antithyroid medications should be contraindicated [10]. Therapies directed at symptomatic relief, i.e. $\beta$-blockers or anxiolytics can be considered in certain patients [7]. Agents that inhibit TSH production without thyromimetic effects can be used to reduce thyroid hormone values. The most widely used medication of this type is $3,3,5$ triiodothyroacetic acid (TRIAC). This medication has been shown to be beneficial in children and adults in some studies [11, 12] and ineffective in others [13]. Compared to exogenous T3, TRIAC does not lead to increase in thyromimetic effects in peripheral tissues because it has a higher affinity for the $\beta$-thyroid hormone receptor, and it is degraded more rapidly [7]. While TRIAC decreases serum TSH and T4 levels, due to its thyromimetic effects, it has minimal effects on markers that measure thyroid hormone action (i.e. SHBG, cholesterol) or heart rate [7]. Currently, TRIAC is not available in North America, and was therefore not a treatment option for our patient.

Dextro-thyroxine (D-T4) has been successful in some cases where TRIAC does not produce desired results [14, 15]. Long-term follow-up over 9 years in a female child showed that TRIAC was more effective than D-T4 in suppressing TSH and lowering thyroid hormone levels in PTHR. Both treatments only led to a modest improvement in symptomatology and neither reduced thyroid size [16].

Dulgeroff et al. [13] reported superior clinical results with bromocriptine compared to TRIAC. Overall, dopaminergic agents and somatostatin analogs have not been shown to effectively reduce TSH production and have undesirable side effects [7]. Thyrotoxic symptoms have variable severity; therefore, some authors suggest periodic cessation of the medications in order to reevaluate the patient's clinical status [5]. Age-related improvement in thyrotoxic symptoms has been reported, perhaps due to decreased sensitivity of peripheral tissues to elevated thyroid hormone over time [16]. Overall, thyroid ablation or surgical resection is not a good option as this may be accompanied by regrowth of thyroid tissue with disruption of the pituitary-thyroid axis.

\section{Benefits of Antithyroid Therapy}

The benefit of using antithyroid medications in patients with THR has not been proven. A case report described female child who was treated with methimazole and then levothyroxine replacement once free T4 levels decreased below the normal range. This patient had a good response to treatment. Specifically, there was improvement in intelligence quotient scores, verbal skills, hyperactivity and weight gain [17]. This clinical picture is similar to that of the patient described in this report, as behavior, development and weight gain showed improvement on methimazole.

Unfortunately, very little literature exists regarding using antithyroid medications in patients with THR. This may be due to previous reports of misdiagnosis of THR with antithyroid medications being used to normalize the thyroid hormone levels resulting in symptoms of thyroid hormone deficiency [6]. Other potential concerns include the theoretical risk of pituitary thyrotropic adenoma development and the belief by some clinicians that it is counterintuitive to use an antithyroid medication in a condition where excess thyroid hormone is a physiological compensation.

Given the positive response in our patient and that described by Kim and Travers [17], the use of methimazole should be considered in patients who have THR with thyrotoxic symptoms. It is essential to recognize the pathophysiology of THR which suggests that thyroid hormone levels should not be normalized but rather maintained above or at the upper end of the normal range depending on symptomatology and other biochemical markers. It is important to monitor for pituitary hyperplasia, reassess clinical signs and symptoms, and follow biochemical markers of thyroid hormone action in such patients. Careful monitoring of sex hormone-binding globulin, cholesterol, ferritin, basal metabolic rate, bone density and urinary hydroxyproline is important as they are markers of thyroid hormone action [7]. The evolving symptoms of THR remain a challenge and warrant close clinical, behavioral and biochemical follow-up.

Future research directions could include further investigation into the success rates of various treatment options and the development of treatment guidelines for this challenging condition. Furthermore, it would be interesting to explore how certain genotypes respond differently to various treatment options. 


\section{References}

1 LaFranchi SH, Snyder DB, Sesser DE, Skeels MR, Singh N, Brent GA, Nelson JC: Followup of newborns with elevated screening T4 concentrations. J Pediatr 2003;143:296-301.

-2 Furlanetto TW, Kopp P, Peccin S, Gu WX, Jameson JL: A novel mutation (M310L) in the thyroid hormone receptor beta causing resistance to thyroid hormone in a Brazilian kindred and a neonate. Mol Genet Metab 2000; 71:520-526.

-3 Magalhaes PK, Rodrigues Dare GL, Rodrigues dos Santos S, Nogueira CR, de Castro M, Zanini Maciel LM: Clinical features and genetic analysis of four Brazilian kindreds with resistance to thyroid hormone. Clin Endocrinol (Oxf) 2007;67:748-753.

- 4 Wu SY, Cohen RN, Simsek E, Senses DA, Yar NE, Grasberger H, Noel J, Refetoff S, Weiss RE: A novel thyroid hormone receptor- $\beta$ mutation that fails to bind nuclear receptor corepressor in a patient as an apparent cause of severe, predominantly pituitary resistance to thyroid hormone. J Clin Endocriol Metab 2006;91:1887-1895.

5 Beck-Peccoz P, Chatterjee VKK: The variable clinical phenotype in thyroid hormone resistance syndrome. Thyroid 1994;4:225232.
6 Refetoff S, Weiss R, Usala SJ: The syndromes of resistance to thyroid hormone. Endocr Rev 1993;14:348-399.

7 Weiss RE, Refetoff S: Treatment of resistance to thyroid hormone - primum non nocere. J Clin Endocrinol Metabl 1999;84:401-404.

$\checkmark 8$ Anselmo J, Refetoff S: Regression of a large goiter in a patient with resistance to thyroid hormone by every other day treatment with triiodothyronine. Thyroid 2004;14:71-74.

$\checkmark 9$ Weiss RE. Dumitrescu A, Refetoff S: Approach to the patient with resistance to thyroid hormone and pregnancy. J Clin Endocrinol Metab 2010;95:3094-3102.

10 Huang SA: Thyroid; in Kappy MS, Allen DB, Geffner ME (eds): Pediatric Practice Endocrinology. Toronto, McGraw-Hill, 2010, pp 107-130.

11 Torre P, Bertoli M, Di Giovanni S, Scommegna S, Conte C, Novelli G, Cianfarani S: Endocrine and neuropsychological assessment in a child with a novel mutation of thyroid hormone receptor: response to 12 month triiodothyroacetic acid (TRIAC) therapy. J Endocrinol Invest 2005;28:657-662.

12 Radetti, G, Persani L, Molinaro G, Mannavola D, Cortelazzi D, Chatterjee VKK, Peck-Peccoz P: Clinical and hormonal outcome after two years of triiodothyroacetic acid treatment in a child with thyroid hormone resistance. Thyroid 1997;7:775-778.
13 Dulgeroff AJ, Geffner ME, Koyal SN, Wong M, Hershman JM: Bromocriptine and Triac therapy for hyperthyroidism due to pituitary resistance to thyroid hormone. J Clin Endocrinol Metab 1992;75:1071-1075.

14 Hamon P, Bovier-Lapierre M, Robert M, Peynaud D, Pugeat M, Orgiazzi: Hyperthyroidism due to selective pituitary resistance to thyroid hormones in a 15-month-old boy: efficacy of D-thyroxine therapy. J Clin Endocrin Metab 1988;67:1089-1093.

15 Dorey F, Strauch G, Gayno JP: Thyrotoxicosis due to pituitary resistance to thyroid hormones. Successful control with D-thyroxine: a study in three patients. Clin Endocrinol 1990;32:221-228.

16 Guran T, Turan S, Bircan R, Bereket A: 9 years follow-up of a patient with pituitary form of resistance to thyroid hormone (PRTH): comparison of two treatment periods of D-thyroxine and triiodothyroacetic acid (TRIAC). J Pediat Endocrinol Metab 2009;22:971-978.

17 Kim J, Travers S: Thyroid hormone resistance and its therapeutic challenges. Curr Opin Pediatr 2008;20:490-493. 